\title{
Quantitative tumor volumetric responses after Gamma Knife radiosurgery for meningiomas
}

\author{
Gillian Harrison, MD, ${ }^{1}$ Hideyuki Kano, MD, PhD, ${ }^{2}$ L. Dade Lunsford, MD, ${ }^{2}$ John C. Flickinger, MD, ${ }^{3}$ \\ and Douglas Kondziolka, MD, MSc ${ }^{1}$
}

\begin{abstract}
1Department of Neurosurgery, New York University Langone Medical Center, New York, New York; and Departments of ${ }^{2}$ Neurological Surgery and ${ }^{3}$ Radiation Oncology, University of Pittsburgh Medical Center, Pittsburgh, Pennsylvania
\end{abstract}

\begin{abstract}
OBJECTIVE The reported tumor control rates for meningiomas after stereotactic radiosurgery (SRS) are high; however, early imaging assessment of tumor volumes may not accurately predict the eventual tumor response. The objective in this study was to quantitatively evaluate the volumetric responses of meningiomas after SRS and to determine whether early volume responses are predictive of longer-term tumor control.

METHODS The authors performed a retrospective review of 252 patients (median age 56 years, range 14-87 years) who underwent Gamma Knife radiosurgery between 2002 and 2010. All patients had evaluable pre- and postoperative T1-weighted contrast-enhanced MRIs. The median baseline tumor volume was $3.5 \mathrm{~cm}^{3}$ (range $0.2-33.8 \mathrm{~cm}^{3}$ ) and the median follow-up was 19.5 months (range 0.1-104.6 months). Follow-up tumor volumes were compared with baseline volumes. Tumor volume percent change and the tumor volume rate of change were compared at 3-month intervals. Eventual tumor responses were classified as progressed for $>15 \%$ volume change, regressed for $\leq 15 \%$ change, and stable for $\pm 15 \%$ of baseline volume at time of last follow-up. Volumetric data were compared with the final tumor status by using univariable and multivariable logistic regression.

RESULTS Tumor volume regression (median decrease of $-40.2 \%$ ) was demonstrated in $168(67 \%)$ patients, tumor stabilization (median change of $-2.7 \%$ ) in $67(26 \%)$ patients, and delayed tumor progression (median increase of 104\%) in $17(7 \%)$ patients $(p<0.001)$. Tumors that eventually regressed had an average volume reduction of $-18.2 \%$ at 3 months. Tumors that eventually progressed all demonstrated volume increase by 6 months. Transient progression was observed in 15 tumors before eventual decrease, and transient regression was noted in 6 tumors before eventual volume increase.

CONCLUSIONS The volume response of meningiomas after SRS is dynamic, and early imaging estimations of the tumor volume may not correlate with the final tumor response. However, tumors that ultimately regressed tended to respond in the first 3 months, whereas tumors that ultimately progressed showed progression within 6 months.
\end{abstract}

http://thejns.org/doi/abs/10.3171/2014.12.JNS141341

KEY WORDS meningioma; stereotactic radiosurgery; Gamma Knife; brain tumor; imaging; response; oncology

$\mathrm{M}$ ENINGIOMAS are the most common primary brain tumors in adults, accounting for more than onethird of all CNS tumors. ${ }^{5,17,37}$ The vast majority of these tumors are nonmalignant, with only $2 \%$ classified as anaplastic or malignant (WHO Grade III) ${ }^{5,37}$ However, with half of tumors diagnosed histologically and half with imaging, ${ }^{37}$ there is great heterogeneity in histological type, aggressiveness, survival, and diagnosis that may make long-term management more complicated. Long-term predictions of outcome can be made using factors such as histological grade and extent of resection. The early response to radiosurgery may be another factor.
Although Grade I and II tumors display different growth patterns, most Grade I tumors grow slowly, with some variability. ${ }^{26,27}$ The primary goal of radiosurgery is often the prevention or alleviation of mass-related symptoms. Traditionally, resection has been the mainstay of therapy for meningiomas when feasible, but in recent decades the use of stereotactic radiosurgery (SRS) as primary or secondary management has become increasingly important in the multimodality care of patients with these tumors. $3,7,34,35,38,42$ Many studies report high rates of success with the use of radiosurgery for meningiomas. For patients receiving adjuvant SRS following resection, progression-

ABBREVIATIONS ARC = absolute rate of change; GKRS = Gamma Knife radiosurgery; PRC = percent rate of change; SRS = stereotactic radiosurgery.

SUBMITTED June 18, 2014. ACCEPTED December 18, 2014.

INCLUDE WHEN CITING Published online July 10, 2015; DOI: 10.3171/2014.12.JNS141341.

DISCLOSURE Dr. Lunsford is a consultant for and stockholder in AB Elekta. This work was supported by funding awarded to the primary author, Dr. Harrison, by the Doris Duke Charitable Foundation. 
free survival rates of $>90 \%$ at minimum 5-year follow-up have been reported. $3,6,7,19,20,23,33,41,42,48$ Comparable rates for those undergoing SRS as primary management have been described. $3,6,9,16,18,19,23,33,34,42,44,48$

In clinical practice, postradiosurgery meningioma follow-up consists of regular outpatient visits and serial imaging analyses. Commonly, clinicians may describe the imaging response categorically as regressed, enlarged, or stable and, if measured, use simple measurements of tumor diameter. Although this evaluation may suffice for immediate management, qualitative descriptions of response do little to characterize the true nature of tumor response after any form of therapy. Additionally, given the heterogeneous nature of meningiomas and the possibility of distant recurrence or delayed malignant progression, ${ }^{4,22}$ quantitative characterization of volume response may assist clinicians in patient risk assessment and long-term clinical decision making. Few prior studies have attempted to quantitatively characterize the nature of meningioma volume response following SRS, and most have focused on long-term changes in absolute volumes. ${ }^{1,7,48}$ The objective of this study was to quantitatively assess the early radiobiological response of meningiomas following SRS and to evaluate volumetric properties as predictors of long-term tumor control.

\section{Methods \\ Study Population}

The University of Pittsburgh Institutional Review Board approved this study. From our database of more than 12,000 patients undergoing Gamma Knife radiosurgery (GKRS) at the University of Pittsburgh Medical Center Presbyterian Hospital, we performed a retrospective cohort study of patients undergoing GKRS for meningiomas between April 2002 and July 2010. Meningiomas were diagnosed using either imaging criteria alone and managed primarily with GKRS or using histological confirmation following prior resection or biopsy. No patients were excluded based on histological tumor grade. Patients were required to have at least one follow-up image suitable for volumetric analysis in the institutional electronic imaging system (which was initiated in 2002) to be included in this study. Patients with prior resection undergoing immediate SRS to the tumor bed, undergoing repeat SRS, or without available or appropriate images in the local imaging system were excluded. Clinical data were obtained through a review of the patients' electronic medical record, the Gamma Knife database, and available imaging studies. Data collected included patient demographic information, clinical history of neurological symptoms, tumor location, prior treatments, and aspects of the radiosurgical dose plan.

\section{Radiosurgery Technique}

Our radiosurgical technique has been described in detail in previous reports. ${ }^{20}$ In brief, radiosurgery was performed under local anesthesia with mild sedation as necessary, using a Leksell Gamma Knife (Elekta Instruments, Inc.). After application of a Leksell model G stereotactic frame, high-resolution, volume acquisition stereotactic MRI studies were obtained. Image-integrated isodose plans were created to enclose the irregular tumor borders.
The dose received by adjacent critical structures was determined and selective beam blocking was used if necessary. The neurosurgeon, radiation oncologist, and medical physicist selected maximal and margin dose. After GKRS, patients were typically discharged on the same day. In general, for WHO Grade I meningiomas, follow-up imaging was planned for 3-6 months after radiosurgery, then at 1-year intervals for the first 2 years, and at intervals of 3-4 years thereafter; earlier imaging may be obtained based on clinical judgment and course.

\section{Tumor Imaging and Volumetric Analysis}

Images suitable for volumetric analysis included axial T1-weighted, gadolinium-enhanced MRIs. When available, high-resolution spoiled gradient echo sequences were used. Slice thicknesses ranged from 1.5 to $5 \mathrm{~mm}$; however, specific sequences and thicknesses varied due to patient preference for follow-up location. On each image slice, tumor surface area was calculated by delineating a freehand region of interest around the contrast-enhancing lesion via institutional radiology software. Cystic portions of the lesion were excluded. Tumor volume was subsequently calculated as the sum of the surface areas multiplied by the slice thickness ${ }^{40}$ (Fig. 1A). Volume was calculated on the day of radiosurgery as a baseline, and then on each followup MRI until the last available scan or until the patient underwent resection or repeat SRS. Volumetric statistics calculated at each follow-up time point include the volume percent change $(\% \Delta \mathrm{V})$ from baseline and the volume rate of change, represented as both an absolute rate of change (ARC), in $\mathrm{cm}^{3} /$ month, and percent rate of change (PRC), in percent/month (Fig. 1B-D).

The final volume available for each patient was compared with the initial, baseline volume for classification into 1 of 3 outcome groups. Tumors that ultimately progressed were defined as those achieving a volume $>15 \%$ above the baseline volume on the final available follow-up image. Tumors that remained stable were defined as those within a range of $\pm 15 \%$ of the baseline volume. Tumors that regressed on the final available image were defined as those achieving a volume $>15 \%$ below the baseline volume. For purposes of analysis, images were grouped into 3 -month intervals.

\section{Statistical Analysis}

Statistical analyses were performed using STATA (version 12.0, StataCorp). Descriptive statistics were used to describe the patient population and treatment variables. Statistical significance was set at $\alpha=0.05$ a priori. The nonparametric Kruskal-Wallis test (for continuous variables) was used to compare volumetric statistics between groups at each 3-month time point. When considering the data as a binomial outcome (progression vs stable or regressed), the nonparametric Wilcoxon rank-sum (for continuous variables) and Fisher exact (for categorical variables) tests were used to correlate demographic and treatment covariates with progression. Multivariable logistic regression was used to analyze volumetric statistics in the first year of follow-up as primary predictors of progression after adjusting for clinical covariates. Regression models were created using covariates that were statisti- 


\section{A $V=\Sigma S A \times$ slicethickness}

B $\% \Delta V=\left(\frac{v o l_{x}-v o l_{0}}{v o l_{0}}\right) \times 100 \%$

C $A R C=\frac{\text { vol }_{x}-\text { vol }_{0}}{\text { time }}=\frac{\mathrm{cm}^{3}}{\text { month }}$

D $P R C=\frac{\% \Delta V}{\text { time }}=\frac{\%}{\text { month }}$

FIG. 1. Equations used to calculate tumor volume (A), percent change in volume from initial volume at time of treatment (B), ARC (C), and PRC (D). $S A=$ surface area.

cally significant on univariable analysis, and only one volumetric statistic was used per model for the purposes of comparison at different time points. Clinically significant interactions and possible confounding variables were addressed. The final model included one volumetric statistic adjusted for follow-up length, age at treatment, treatment percent isodose, baseline volume, and history of resection.

\section{Results}

\section{Clinical Characteristics and Treatment Parameters in the Study Population}

We identified 676 patients who underwent GKRS between 2002 and 2010, and of this cohort 252 patients (37\%) were included in this study. The remainder were excluded for lack of appropriate intrainstitutional imaging for volumetric analysis, GKRS to a resection bed, or repeat GKRS. The median age at time of radiosurgery was 56.4 years (range 14.6-87.6 years), 73\% were female, and $27 \%$ were male. Of 88 patients $(35 \%)$ with a history of either resection or biopsy, $97 \%$ were classified as WHO Grade I. In this group, 2 patients had biopsy results showing pathological features consistent with WHO Grade I meningioma. Of these 2 patients, 1 underwent resection and subsequent GKRS for eventual recurrence. The other underwent GKRS as primary management. Of 87 patients with prior resection, 27 underwent gross-total resection and were treated with GKRS for tumor recurrence. Sixty patients had prior subtotal resection and were treated with GKRS for residual or recurrent tumor. Presenting symptoms included headache $(22 \%)$, seizure $(10 \%)$, and focal neurological deficit $(33 \%)$ such as cranial nerve palsies, focal weakness, or sensory changes. The mean symptom duration prior to GKRS was 2.9 months (SD 5.3 months). Distribution of tumor location is provided in Table 1. The SRS parameters are summarized in Table 2 . The median target volume was $2.0 \mathrm{~cm}^{3}$ (range $0.12-25.4 \mathrm{~cm}^{3}$ ), and the SRS dose to the tumor margin varied from 10 to $18 \mathrm{~Gy}$ prescribed to the $40 \%-70 \%$ isodose line. A representative case demonstrating the region of interest and dose planning is described in Fig. 2.
TABLE 1. Summary of demographic and tumor data for 252 patients with meningiomas

\begin{tabular}{cc}
\hline Characteristic & Value (\%) \\
\hline Age at GKRS, in yrs & \\
Median & 56.4 \\
Range & $14.6-87.6$ \\
Sex & \\
Male & $69(27)$ \\
Female & $183(73)$ \\
\hline Tumor grade & \\
WHO Grade I & $85(34)$ \\
WHO Grade II/III & $3(1)$ \\
Unknown & $164(65)$ \\
\hline Tumor location & \\
Cavernous sinus & $42(17)$ \\
Cerebellar & $20(8)$ \\
Frontoparietal & $106(42)$ \\
Intraventricular & $4(2)$ \\
Occipital & $12(5)$ \\
Skull base & $37(15)$ \\
Temporal & $14(6)$ \\
Other & $17(7)$ \\
\hline Symptoms & \\
Headache & $55(22)$ \\
Seizure & $26(10)$ \\
Neurological deficit & $82(33)$ \\
History of surgery & \\
Resection & $26(34)$ \\
Biopsy &
\end{tabular}

\section{Descriptive Volumetric Analysis}

At the time of SRS, the median baseline tumor volume for the study population was $3.54 \mathrm{~cm}^{3}$ (range $0.21-33.84$ $\mathrm{cm}^{3}$ ). After a mean follow-up of 28.16 months ([SD 23.86], median 19.50, range 0.07-104.61 months) the mean reduction in tumor volume was $-20.47 \%$ ([SD $47.88 \%$ ], median $-29.87 \%$, range $-87.63 \%$ to $405.13 \%$ ) to reach a median final tumor volume of $2.62 \mathrm{~cm}^{3}$ (range $0.12-64.69 \mathrm{~cm}^{3}$ ) that differed significantly from baseline $(\mathrm{p}<0.001)$ (Table 3 ). Over the course of the first year, the mean $\% \Delta \mathrm{V}$ steadily decreased, from an average of $-20.5 \%$ in the first 3 months post-SRS until a gradual nadir of $-38.7 \%$ was reached at 33 months (Fig. 3).

Of the 252 meningiomas irradiated, 168 (67\%) ultimately regressed, 67 (26\%) remained stable, and 17 (7\%) ultimately progressed; tumors in these categories were defined as achieving a volume on the final available followup image of $\mathrm{V}<85 \%, \mathrm{~V} \geq 85 \%$ but $\leq 115 \%$, or $\mathrm{V}>115 \%$, respectively. Baseline volumes were similar in each group $(\mathrm{p}=0.482)$, and final volumes were significantly larger in tumors that progressed $(\mathrm{p}<0.001)$, supporting the use of a $\Delta \mathrm{V}$ of $15 \%$ as a cutoff for progression. Tumors that regressed did so a median of $-1.27 \mathrm{~cm}^{3}$ (range -12.05 to $-0.11 \mathrm{~cm}^{3}$ ) or $-36.37 \%$ (range $-87.63 \%$ to $-15.52 \%$ ) over the course of median 24.33-month follow-up (range 2.14104.61 months). In contrast, those tumors that remained stable regressed a median of $-4.35 \%$ (range $-14.79 \%$ to $15.00 \%$ ), and meningiomas that ultimately progressed displayed an absolute median increase of $2.49 \mathrm{~cm}^{3}$ (range 
TABLE 2. Summary of SRS parameters for 252 meningiomas

\begin{tabular}{ll}
\hline \multicolumn{1}{c}{ Parameter } & \multicolumn{1}{c}{ Value } \\
\hline Treatment vol in $\mathrm{cm}^{3}$, median (range) & $2.0(0.12-25.4)$. \\
\hline Radiation maximum dose in Gy, median (range) & $25.5(20-36)$ \\
\hline Prescribed isodose \%, median (range) & $50(40-70)$ \\
\hline $\begin{array}{l}\text { Prescribed margin radiation dose in Gy, median } \\
\text { (range) }\end{array}$ & $13(10-18)$ \\
\hline Perfexion unit count (\%) & $53(21)$ \\
\hline
\end{tabular}

$0.39-45.78 \mathrm{~cm}^{3}$ ) or $66.57 \%$ (range $16.61 \%-405.13 \%$ ) over 35 months (range $0.18-89.92$ months) ( $\mathrm{p}<0.001$, Table 3$)$. Over the course of the first follow-up year post-SRS, there were 55, 141, and 47 observations available for analysis at the 3-, 6-, and 12-month time points. The mean $\% \Delta \mathrm{V}$ became significantly different by 3 months, with continued diversion up to 33 months (Table 4 and Fig. 4).

\section{Volumetric Rate of Change}

Meningiomas that regressed demonstrated a decrease of $-18.17 \%$ (SD $23.99 \%$ ), with a maximum rate of -0.57 (SD 0.72) $\mathrm{cm}^{3} /$ month or $-6.39 \% /$ month (SD $10.10 \% /$ month) in the first 3 months post-SRS. The regression response stabilized after approximately 6 months (Table 4). In contrast, meningiomas that progressed showed a mild early response to therapy, with a mean decline of $-2.87 \%$ (SD 2.87\%) at a rate of -0.11 (SD 0.11 ) $\mathrm{cm}^{3} /$ month or $-0.85 \% /$ month (SD $0.85 \% /$ month), and then exhibited a mean increase in size of $13.86 \%$ (SD $48.28 \%$ ) by 6 months after treatment. This pattern did not always hold true. Transient enlargement was observed in 15 tumors before eventual response to SRS, and transient regression was observed in 6 tumors prior to treatment failure. Variability in rate of change was highest in the immediate postoperative months, with a trend toward stability in the 6- to 12-month post-SRS period (Fig. 5).

\section{Analysis of Tumor Progression}

The mean time to progression for 17 tumors was 36.74 months (SD 26.91, median 30.33, range 5.30-91.23 months). The 2- and 5-year tumor control rates were $95 \%$ (95\% CI 94-99) and 85\% (95\% CI 74-92), respectively (Fig. 6); there were 168 (67\%), 118 (47\%), and 16 (6\%) tumors available for analysis at 1,2, and 5 years of follow-up, respectively. Although approximately one-third of tumors in this group initially displayed some response to therapy, overall growth was observed by 6 months post-SRS. The median patient age was 64 years (range 33-87 years), $76 \%$ were female, and $24 \%$ were male. A majority of patients $(64 \%)$ had a history of resection, and 10 of their 11 tumors were WHO Grade I. Following failure of SRS, 5 patients $(29 \%)$ underwent resection and $6(35 \%)$ underwent repeat SRS (Table 5).

On univariable analysis, patient and treatment parameters that were predictive of progression included older age $(\mathrm{p}<0.001)$, smaller treatment volume $(\mathrm{p}=0.032)$, lower $\%$ isodose $(\mathrm{p}<0.001)$, history of surgery $(\mathrm{p}<0.001)$, higher tumor grade $(\mathrm{p}<0.001)$, and longer length of follow-up $(\mathrm{p}=0.047)$. Volumetric statistics predictive of progression included higher initial tumor volume $(\mathrm{p}<0.001), \% \Delta \mathrm{V}$ (overall $\mathrm{p}<0.001$, at 6 months $\mathrm{p}=0.009$, at 12 months $\mathrm{p}=$ 0.033 ), ARC (overall $\mathrm{p}=0.017$, at 12 months $\mathrm{p}=0.05$ ), and PRC (overall $\mathrm{p}=0.009$, at 6 months $\mathrm{p}=0.016$ ).

The final multivariable model used volumetric statistics, including $\% \Delta \mathrm{V}, \mathrm{ARC}$, and PRC, as primary predictors of progression adjusted for age, initial tumor volume, follow-up length, \% isodose, and history of surgery. Regardless of volumetric parameter included, older age ( $p$ $<0.001-0.021)$ and greater initial tumor volume $(\mathrm{p}<$ 0.001 ) remained predictors of progression, whereas longer

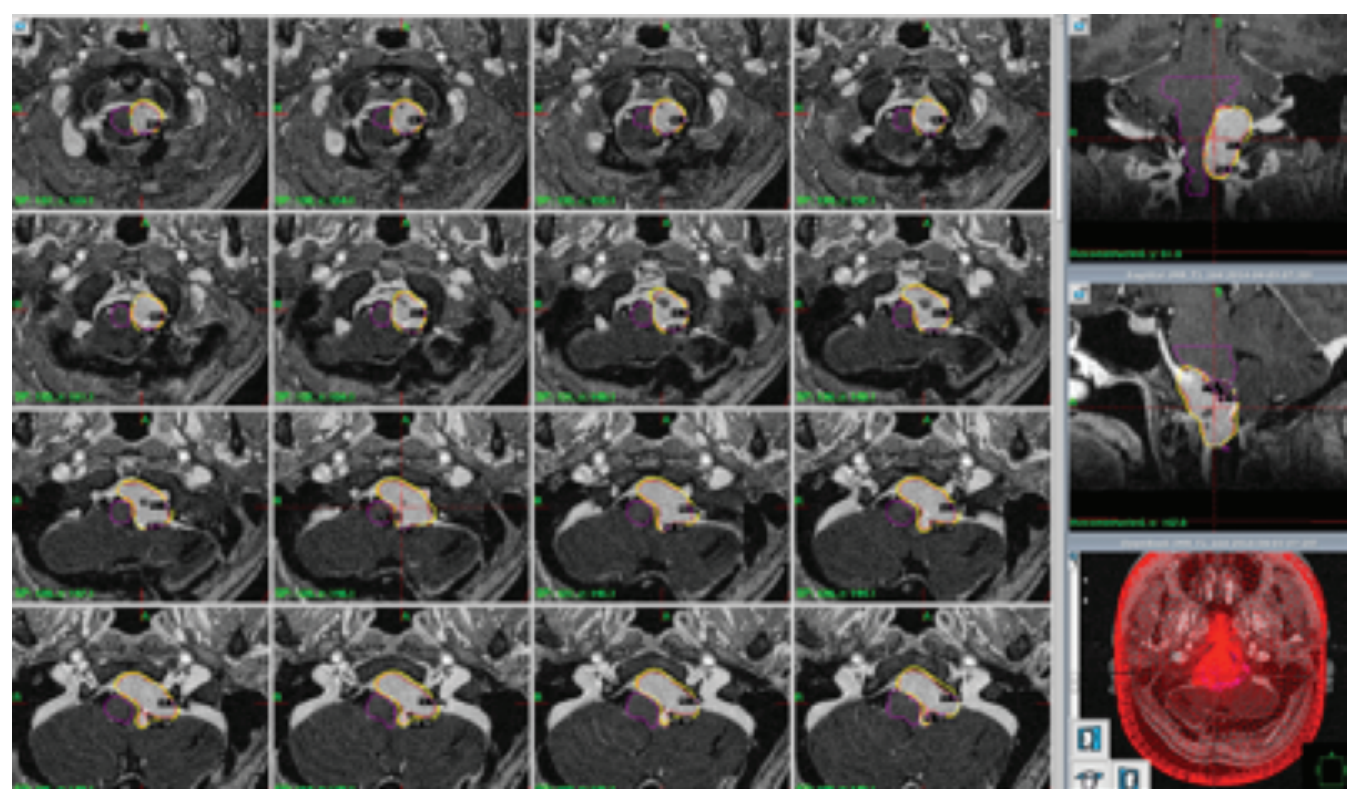

FIG. 2. Axial, coronal, and sagittal radiosurgery dose plan images showing a recurrent left foramen magnum meningioma. The radiosurgery dose plan is shown with volumetric contours of the tumor and brainstem. Figure is available in color online only. 
TABLE 3. Summary of tumor volume data by outcome group*

\begin{tabular}{lccccc}
\hline \multicolumn{1}{c}{ Vol Parameter } & Overall & Regressed $(n=168)$ & Stable $(n=67)$ & Progressed $(n=17)$ & $p$ Value† \\
\hline Initial tumor vol $\left(\mathrm{cm}^{3}\right)$ & $3.54(0.21-33.84)$ & $3.28(0.37-26.50)$ & $4.36(0.21-27.20)$ & $4.29(0.30-33.84)$ & 0.482 \\
\hline Final tumor vol $\left(\mathrm{cm}^{3}\right)$ & $2.62(0.12-64.69)$ & $1.85(0.12-18.16)$ & $3.86(0.24-26.76)$ & $7.32(0.98-64.69)$ & $<0.001$ \\
\hline Final vol absolute change $\left(\mathrm{cm}^{3}\right)$ & $-0.79(-12.05$ to 45.78$) \ddagger$ & $-1.27(-12.05$ to -0.11$)$ & $-0.09(-2.28$ to 3.23$)$ & $2.49(0.39-45.78)$ & $<0.001$ \\
\hline Final \% $\Delta V(\%)$ & $-29.87(-87.63$ to 405.13$)$ & $-36.37(-87.63$ to -15.52$)$ & $-4.35(-14.79$ to 15.0$)$ & $66.57(16.61-405.13)$ & $<0.001$ \\
\hline Length of follow-up (mos) & $19.50(0.07-104.61)$ & $24.33(2.14-104.61)$ & $11.37(0.07-70.41)$ & $34.96(0.18-89.92)$ & $<0.001$ \\
\hline
\end{tabular}

* Data are presented as the median (range); units of measure for individual entries are given in parentheses in the first column.

$\dagger$ According to the Kruskal-Wallis test.

$\ddagger$ Final volume significantly different from initial volume $(p<0.001)$ according to the Wilcoxon signed-rank test for equality of medians.

follow-up was significant when adjusting for $\% \Delta \mathrm{V}(\mathrm{p}=$ $0.038)$ and PRC ( $\mathrm{p}=0.05), \%$ isodose when adjusting for PRC $(\mathrm{p}=0.035)$, and history of surgery when adjusting for ARC $(p=0.001)$ and PRC $(p=0.002)$. No volumetric statistics were significant predictors of progression at 3 months post-SRS. At 6 months, $\% \Delta \mathrm{V}$ and PRC were predictive of ultimate progression, with odds ratios of 1.04 (95\% CI 1.01-1.07, $\mathrm{p}=0.007)$ and 1.18 (95\% CI 1.04-1.35, $\mathrm{p}=0.012$ ), respectively. Similarly, at 12 months post-SRS the ARC was predictive of progression $(p=0.049)$ and there was a trend toward significance for $\% \Delta \mathrm{V}$.

\section{Discussion}

Stereotactic radiosurgery is highly efficacious and safe in the management of intracranial meningiomas. Longterm data, including series describing clinical and imaging outcomes more than 10 years from radiosurgery $y^{11,15,36,39}$, $43,45,48$ have demonstrated favorable control rates using SRS as both primary and adjuvant care. Response to treatment, however, is often clinically described categorically, as regressed, enlarged, or stable, which crudely characterizes the true nature of the tumor response. To better understand the radiobiological response to radiosurgery we need to accurately measure that response. What may appear to be subtle changes in linear measurements can be less subtle changes in volume. Understanding the early response profile may assist in predicting longer-term outcomes and may provide clues to help improve the overall outcome.

Volumetric changes of neoplasms after radiosurgery provide insight into a specific tumoral response. Prior investigations in small clinical series have evaluated such responses to radiosurgery in meningiomas, schwannomas, pituitary adenomas, gliomas, and brain metastases. ${ }^{8,12,28,46}$ Some of these studies are limited to a degree by a simplified methodology for volumetric measurement. Most commonly a geometrical method using the equation for volume of a sphere, $\mathrm{XYZ} *(\pi / 6)$, and the maximum tumor diameter in the $\mathrm{X}, \mathrm{Y}$, and $\mathrm{Z}$ planes is used; ${ }^{14,25,31}$ however, lesional irregularities may compromise such methods, and error rates as high as $20 \%$ have been reported. ${ }^{30,47}$ In contrast, volume measurement performed using the product of tumor surface area and slice thickness has been shown to be more accurate overall. ${ }^{14,30}$

Here we use this more precise volume measurement on serial post-SRS imaging, with the objective of quantitatively assessing the early radiobiological response of meningiomas following SRS, and evaluating the volumetric parameters as predictors of long-term tumor control. Of
252 tumors with median baseline volume of $3.54 \mathrm{~cm}^{3}, 168$ (67\%) regressed to $<85 \%$ of baseline volume, $67(26 \%)$ remained within $15 \%$ of baseline volume, and $17(7 \%)$ progressed to $>115 \%$ of baseline volume, to a median final volume of $2.62 \mathrm{~cm}^{3}$ over median follow-up of 19.50 months. If classifying the control rate based on regression and stability, this results in a $94 \%$ control rate overall, which is in line with current literature. . $, 67,9,16,18,19,23,33,34,42,44,48^{2}$

Tumors that regressed demonstrated a median absolute volume change of $-1.27 \mathrm{~cm}^{3}(-36.37 \%)$ at final follow-up, with the greatest rate of change in the first 3 months postSRS. Few studies have specifically addressed volumetric changes in meningiomas following SRS. Allowing for differences in methodology, specifically the use of a $10 \%$ change in volume as a definition of regression/progression, Feigl and colleagues identified comparable rates of regression in 2 studies of meningiomas treated with SRS.7.8 In the earlier series, a similar overall control rate of $96.4 \%$ was noted. Ultimate regression was identified in $82.4 \%$ of the cohort, with mean absolute reduction of $2.1 \mathrm{~cm}^{3}$, or $46.1 \%$. The second series similarly identified regression in $74.5 \%$ of the cohort, with absolute reduction of $2.1 \mathrm{~cm}^{3}$, or $42.1 \% .{ }^{8}$ Regression in both series was identified as early as 3 months post-SRS, which highlights the importance of early volumetric analysis after treatment. Similarly, Park et al. observed that $86.7 \%$ of meningiomas that regressed

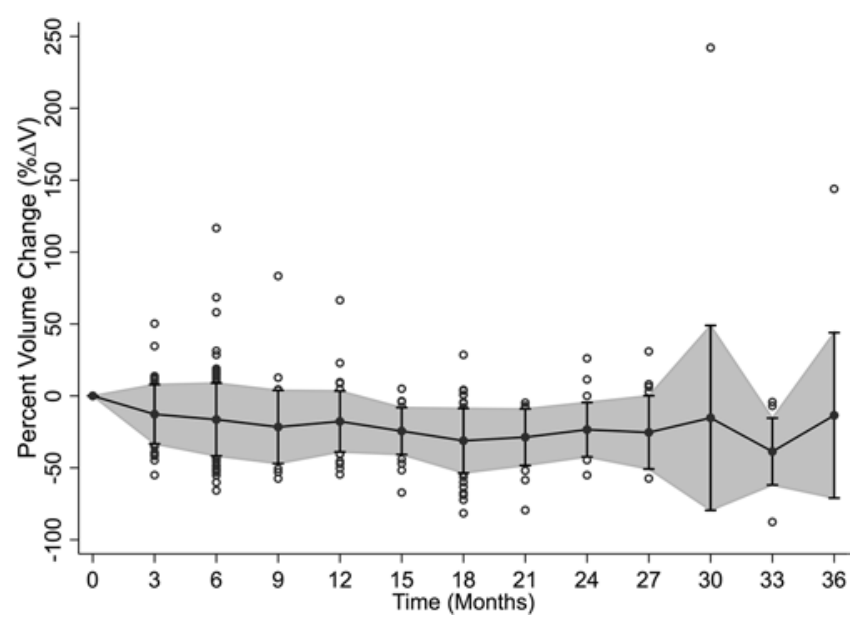

FIG. 3. The mean $\% \Delta V$ from initial volume (solid circles) \pm 1 SD over time, overlaid with a scatter plot of individual tumor data for 252 meningiomas following treatment with SRS. A mean decrease of $-20.5 \%$ was observed by 3 months post-SRS, with continued shrinkage to a nadir of $-38.7 \%$ at 33 months. 
TABLE 4. Tumor volumetric statistics in the first postradiosurgery year in 252 patients with meningiomas*

\begin{tabular}{|c|c|c|c|c|c|}
\hline Vol Parameter & Overall & Regressed $(n=168)$ & Stable $(n=67)$ & Progressed $(n=17)$ & $p$ Value $†$ \\
\hline \multicolumn{6}{|l|}{$3 \mathrm{Mos}$} \\
\hline Vol $\left(\mathrm{cm}^{3}\right)$ & $8.51(7.00)$ & $6.16(4.47)$ & $12.04(8.80)$ & $12.17(12.17) \ddagger$ & 0.032 \\
\hline$\% \Delta \mathrm{V}(\%)$ & $-20.49(22.61)$ & $-18.17(23.99)$ & $-1.71(8.77)$ & $-2.87(2.87) \ddagger$ & $<0.001$ \\
\hline $\operatorname{ARC}\left(\mathrm{cm}^{3} / \mathrm{mo}\right)$ & $-0.46(1.33)$ & $-0.57(0.72)$ & $-0.31(1.96)$ & $-0.11(0.11) \ddagger$ & 0.042 \\
\hline $\mathrm{PRC}(\% \Delta \mathrm{V} / \mathrm{mo})$ & $-3.31(25.83)$ & $-6.39(10.10)$ & $1.40(39.99)$ & $-0.85(0.85) \ddagger$ & 0.005 \\
\hline \multicolumn{6}{|l|}{6 Mos } \\
\hline Vol $\left(\mathrm{cm}^{3}\right)$ & $4.33(4.26)$ & $3.74(3.67)$ & $5.53(5.11)$ & $4.62(4.85)$ & 0.145 \\
\hline$\% \Delta \mathrm{V}(\%)$ & $-22.49(47.13)$ & $-25.57(20.38)$ & $0.25(17.35)$ & $13.86(48.28)$ & $<0.001$ \\
\hline $\operatorname{ARC}\left(\mathrm{cm}^{3} / \mathrm{mo}\right)$ & $-0.13(0.39)$ & $-0.22(0.32)$ & $0.05(0.47)$ & $0.04(0.21)$ & $<0.001$ \\
\hline PRC $(\% \Delta \mathrm{V} / \mathrm{mo})$ & $-2.60(5.27)$ & $-4.53(4.44)$ & $0.70(4.33)$ & $2.23(7.75)$ & $<0.001$ \\
\hline \multicolumn{6}{|l|}{9 Mos } \\
\hline Vol $\left(\mathrm{cm}^{3}\right)$ & $5.19(4.59)$ & $4.76(3.79)$ & $5.97(5.54)$ & $9.61(12.92)$ & 0.932 \\
\hline$\% \Delta \mathrm{V}(\%)$ & $-25.89(43.26)$ & $-25.87(15.33)$ & $0.81(9.48)$ & $15.21(96.38)$ & 0.036 \\
\hline $\mathrm{ARC}\left(\mathrm{cm}^{3} / \mathrm{mo}\right)$ & $-0.17(0.39)$ & $-0.22(0.37)$ & $-0.08(0.23)$ & $0.39(0.64)$ & 0.246 \\
\hline $\mathrm{PRC}(\% \Delta \mathrm{V} / \mathrm{mo})$ & $-3.23(5.67)$ & $-3.60(5.67)$ & $-2.53(3.61)$ & $0.66(10.70)$ & 0.921 \\
\hline \multicolumn{6}{|l|}{12 Mos } \\
\hline $\operatorname{Vol}\left(\mathrm{cm}^{3}\right)$ & $4.52(4.11)$ & $4.13(3.67)$ & $4.86(4.36)$ & $6.24(6.65)$ & 0.656 \\
\hline$\% \Delta \mathrm{V}(\%)$ & $-19.99(24.28)$ & $-27.44(13.04)$ & $-8.90(11.83)$ & $18.47(37.90)$ & $<0.001$ \\
\hline $\operatorname{ARC}\left(\mathrm{cm}^{3} / \mathrm{mo}\right)$ & $-0.21(1.23)$ & $-0.36(1.55)$ & $0.02(0.18)$ & $0.14(0.23)$ & 0.019 \\
\hline $\mathrm{PRC}(\% \Delta \mathrm{V} / \mathrm{mo})$ & $-2.28(9.75)$ & $-3.83(11.62)$ & $-0.77(3.89)$ & $3.61(7.12)$ & 0.011 \\
\hline
\end{tabular}

* Data are presented as the mean (SD); units of measure for individual entries are given in parentheses in the first column.

† According to the Kruskal-Wallis test.

‡ Data were only available for 1 tumor in the 3-month period.

did so in the first 12 months post-SRS, with half of those demonstrating reduction in the first 6 months. ${ }^{31}$ Henzel and colleagues observed a significant mean regression of $16.6 \%$ in the first 6 months post-SRS and identified a comparable trend in regression, with the most rapid response in the first 6 months. ${ }^{13}$ In contrast, Astner et al. did not ob-

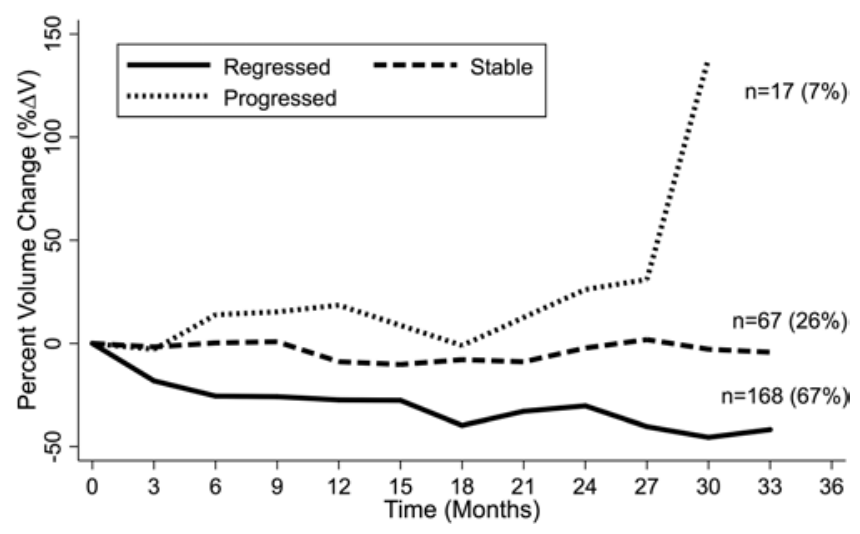

FIG. 4. The mean $\% \Delta V$ by outcome group. The mean $\% \Delta V$ from initial volume following SRS separated by tumors that ultimately regressed (solid line, $n=168$ ) to $<85 \%$ of the initial volume; remained stable (dashed line, $n=67$ ) within $\pm 15 \%$ of initial volume; and those that progressed (dotted line, $n=17$ ) to $>115 \%$ of initial volume. Tumor volume changes became significantly different at 6 months, with continued divergence through the remaining follow-up periods. Ultimately, tumors that regressed shrank a mean of $-45.6 \%$ at 30 months post-SRS, compared with $-2.8 \%$ for those that remained stable and $138.1 \%$ for those that progressed $(p<0.001)$. serve volume reduction until 11 months posttreatment, and they only noted a mean regression of $27 \%$. Of note, however, the cohort was composed mainly of meningiomas treated with fractionated stereotactic radiotherapy and, of 6 tumors treated with radiosurgery, a median volume reduction of $44 \%$ was observed. ${ }^{1}$

We identified a small percentage of tumors that demonstrated variable response trends post-SRS. Transient enlargement was observed in $9 \%$ of tumors that ultimately regressed (6\% overall), and transient regression was seen in $35 \%$ of those that ultimately progressed (2.4\% overall). Whereas partial treatment response prior to progression may conform to an expected response pattern, transient enlargement prior to regression may be puzzling. Interestingly, this response pattern has been noted in prior studies of both meningiomas ${ }^{8,18,29,31}$ and other tumor pathological types. ${ }^{25,31}$ This observation can be related to transient tumoral expansion while the tumor center is responding to the targeted injury and the response is mediated via inflammation, with changes that vary with length of time postradiosurgery. ${ }^{18,24,31}$

The mean time to documented progression for 17 tumors was 37.74 months; however, initial growth above the baseline volume was observed by 6 months post-SRS. Data from prior studies on time to progression vary significantly, with reported means from 82 to 90 months and ranges from 10 to 144 months. ${ }^{10,11,15,18,21,48}$ Volumetric studies of meningioma response have identified much shorter times to progression, with evidence of growth as early as 4-10 months post-SRS. ${ }^{8,31}$ Much of this discrepancy, however, may be attributable to definitions of progression, tu- 


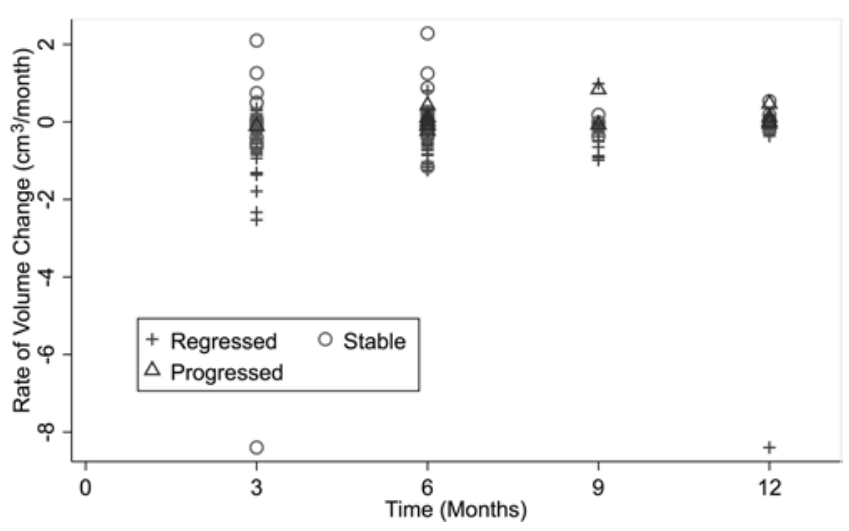

FIG. 5. Scatter plot of volume ARC $\left(\mathrm{cm}^{3} /\right.$ month) in the first postradiosurgical year, separated by outcome group. There is increased variability in rate in the first 3 months (mean $-0.46 \pm 1.33 \mathrm{~cm}^{3} /$ month), with stabilization in the rate of change after 6 months. Meningiomas that regressed exhibited a mean change of $-18.2 \%$ and a maximum rate of change in the first 3 months (mean $-0.57 \pm 0.72 \mathrm{~cm}^{3} /$ month or $6.39 \pm 10.10 \% /$ month). In contrast, tumors that ultimately progressed exhibited minor initial regression, with a mean of $-2.87 \%$, but a slower rate of change $\left(-0.11 \mathrm{~cm}^{3} /\right.$ month or $-0.85 \% /$ month).

mor location and grade, and radiation dose, because many of these studies defined progression categorically, specifically examined meningiomas of the skull base or cavernous sinus, and limited cohorts based on WHO grade or radiation dose. Multiple studies have addressed meningioma outcomes based on location, and have noted that there may be variability between different cranial base locations. ${ }^{10,42}$ Grade II/III meningiomas tend to occur at the cerebral convexity or parasagittal location, and exhibit poorer treatment response and clinical outcomes in longterm follow-up., ${ }^{2,20,32,35}$ Our series included a high percentage of meningiomas that had been diagnosed on neuroimaging and a high percentage of basal and cavernous sinus tumors which, taken together, suggest a high percentage of WHO Grade I meningiomas and contribute to the favorable outcomes in our series; nonetheless, identification of progression at 40 months is significantly less than the means of 80-90 months reported in the literature. This may indicate a higher sensitivity for detection of progression with volumetric analysis.

We identified older age and larger initial tumor volume as consistently significant predictors of progression on multivariable analysis, with longer follow-up, isodose, and history of surgery of variable significance based on the regression model. These findings are consistent with several prior studies; ${ }^{13,18,20,35,41,42}$ however, many failed to identify pretreatment- or treatment-related factors associated with progression. . $^{1,69,31,34} \mathrm{~A}$ unique aspect of our study was the use of volumetric statistics as predictors of tumor progression. We found that initial volume, change in volume, and rate of change could be used to predict progression, most significantly in the 6- to 12-month follow-up range. In Astner et al.'s series of 59 patients, none of whom demonstrated progression over a mean follow-up of 50 months, tumor regression was not time dependent. The authors reported a volume reduction of $17 \%, 23 \%$, and $30 \%$ at $<24,24-48$, and 48-72 months posttreatment, respectively, with a tendency toward increased reduction after a longer time, al-

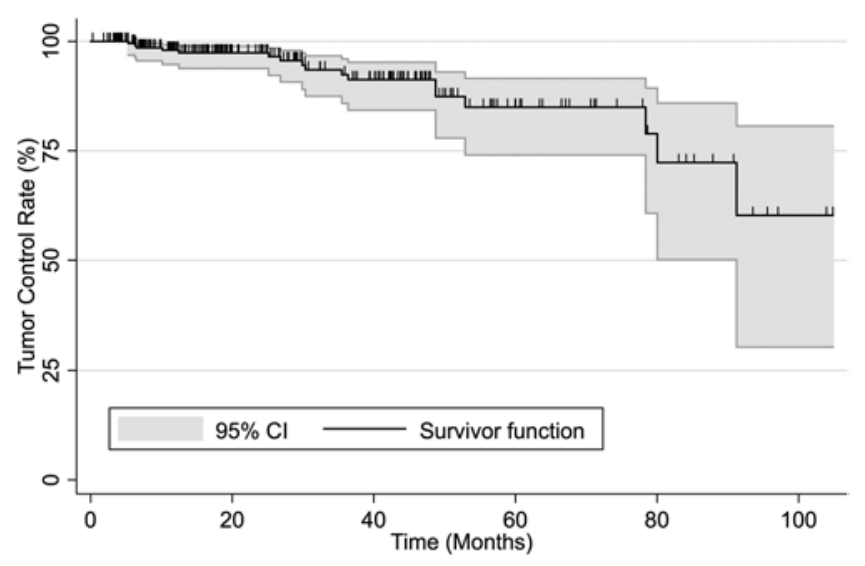

FIG. 6. Kaplan-Meier curve of tumor control rates in 252 patients with meningiomas treated using GKRS demonstrating a 2-year control rate of $97 \%$.

though no significant trend was identified. ${ }^{1}$ In contrast, in their prospective study of 84 meningiomas, Henzel et al. demonstrated similar regression trends to our series, with $16.6 \%, 24.5 \%, 27.9 \%, 33.2 \%$, and $36 \%$ tumor reduction at $6,12,18,24$, and 36 months, respectively. They found that over the first 3 years post-SRS, tumor volume was reduced continuously toward a steady state, presumably achieved later than 3 years after treatment. We similarly identified a continuous volume reduction in tumors that ultimately regressed. However, we additionally documented the rate

TABLE 5. Summary of clinical characteristics in 17 patients with tumor progression

\begin{tabular}{lc}
\hline \multicolumn{1}{c}{ Characteristic } & Value $(\%)$ \\
\hline Age in yrs & 64 \\
Median & $33-87$ \\
Range & \\
Sex & $4(24)$ \\
Male & $13(76)$ \\
Female & \\
Tumor grade & $10(59)$ \\
WHO Grade I & $1(6)$ \\
WHO Grade II/III & $6(35)$ \\
Unknown & \\
\hline Tumor location & $5(29)$ \\
Cavernous sinus & $6(35)$ \\
Frontoparietal & $3(18)$ \\
Posterior fossa & $1(6)$ \\
Skull base & $2(12)$ \\
Temporal & \\
Symptoms & $3(18)$ \\
Headache & $5(29)$ \\
Neurological deficit & \\
History of surgery & $11(64)$ \\
Resection & $8(47)$ \\
Subsequent treatment & $3(18)$ \\
None & $4(23)$ \\
Resection & $2(12)$ \\
Repeat radiosurgery & \\
Resection \& radiosurgery & \\
\hline & \\
\hline & \\
\hline & \\
\hline & \\
\hline & \\
\hline &
\end{tabular}


of change and noted that tumors that regressed tended to do so more quickly in the first 6 months, and then continued at a slower and more constant rate afterward. This was in contrast to the mild volume reduction and slower rate of change initially exhibited by those that ultimately progressed.

\section{Study Limitations}

As noted above, tumor location and pathological features may influence the response to radiosurgery. In our cohort the tumors were of mixed location, and many did not have histological confirmation of the diagnosis. The retrospective nature of this study conveys significant bias, with subsequent limitation in interpretation of results, particularly for long-term results. In general, follow-up MRIs are planned at 3-6 months and 1 year post-GKRS; however, the actual timing of initial follow-up MRI in our cohort was extremely variable, ranging from within days of treatment to months later. Part of this may be due to the extremely geographically diverse patient population our center treats, but there are many patient- and diseaserelated factors that may prompt earlier imaging and could confound results. Additionally, follow-up was limited to imaging obtainable in our institution's system to provide a uniform data set, thus resulting in a selection bias for patients obtaining follow-up within our hospital network. The effects of limitations inherent in a retrospective study, particularly irregular scheduling of follow-up imaging and widely varying length of follow-up, are particularly evident in our long-term follow-up results, as evidenced in the Kaplan-Meier curve; a 5-year control rate of $85 \%$ is lower than expected based on prior literature and may in large part be attributed to the significant number of censored cases due to limited follow-up.

Technical limitations also exist secondary to retrospective analysis of imaging. Slice thickness and type and/or dose of gadolinium can contribute to variability, and this factor cannot be controlled retrospectively. Studies analyzing the effect of shape and number of slices on accuracy of volume calculation have demonstrated increasing error with irregular or rectangular shape and decreasing number of slices, with errors in the 10\%-20\% range for irregular or rectangular shapes and 5-10 slices. ${ }^{47}$ Furthermore, an increase in the volume of contrast enhancement does not necessarily indicate tumor growth. Instead, it may reflect inflammatory blood-brain barrier changes as part of the cytokine-mediated tumor injury response. This could misclassify progression and reinforces the need for serial imaging.

\section{Conclusions}

Stereotactic radiosurgery for meningiomas can be used effectively to not only control growth, but also to reduce tumor volume in the first year after treatment. The volume response of meningiomas after SRS is dynamic, and early changes may not be directly indicative of long-term tumor response. Our results suggest that meningiomas that ultimately regress tend to show response in the first 3 months, whereas those that ultimately progress tend do so within 6 months. Quantitative volumetric assessment of tumor response to SRS may help clinicians to better understand early response profiles and provide a valuable tool for patient management following SRS for meningiomas.

\section{References}

1. Astner ST, Theodorou M, Dobrei-Ciuchendea M, Auer F, Kopp C, Molls M, et al: Tumor shrinkage assessed by volumetric MRI in the long-term follow-up after stereotactic radiotherapy of meningiomas. Strahlenther Onkol 186:423429,2010

2. Bledsoe JM, Link MJ, Stafford SL, Park PJ, Pollock BE: Radiosurgery for large-volume $(>10 \mathrm{~cm} 3)$ benign meningiomas. J Neurosurg 112:951-956, 2010

3. Bloch O, Kaur G, Jian BJ, Parsa AT, Barani IJ: Stereotactic radiosurgery for benign meningiomas. J Neurooncol 107:13-20, 2012

4. Couldwell WT, Cole CD, Al-Mefty O: Patterns of skull base meningioma progression after failed radiosurgery. J Neurosurg 106:30-35, 2007

5. Dolecek TA, Propp JM, Stroup NE, Kruchko C: CBTRUS statistical report: primary brain and central nervous system tumors diagnosed in the United States in 2005-2009. Neuro Oncol 14 (Suppl 5):v1-v49, 2012

6. dos Santos MA, de Salcedo JB, Gutiérrez Diaz JA, Calvo FA, Samblás J, Marsiglia H, et al: Long-term outcomes of stereotactic radiosurgery for treatment of cavernous sinus meningiomas. Int J Radiat Oncol Biol Phys 81:1436-1441, 2011

7. Feigl GC, Bundschuh O, Gharabaghi A, Samii M, Horstmann GA: Volume reduction in meningiomas after gamma knife surgery. J Neurosurg 102 Suppl:189-194, 2005

8. Feigl GC, Samii M, Horstmann GA: Volumetric follow-up of meningiomas: a quantitative method to evaluate treatment outcome of gamma knife radiosurgery. Neurosurgery 61:281-286, 2007

9. Flickinger JC, Kondziolka D, Maitz AH, Lunsford LD: Gamma knife radiosurgery of imaging-diagnosed intracranial meningioma. Int J Radiat Oncol Biol Phys 56:801-806, 2003

10. Han JH, Kim DG, Chung HT, Park CK, Paek SH, Kim CY, et al: Gamma knife radiosurgery for skull base meningiomas: long-term radiologic and clinical outcome. Int J Radiat Oncol Biol Phys 72:1324-1332, 2008

11. Hasegawa T, Kida Y, Yoshimoto M, Koike J, Iizuka H, Ishii D: Long-term outcomes of Gamma Knife surgery for cavernous sinus meningioma. J Neurosurg 107:745-751, 2007

12. Hayhurst C, Zadeh G: Tumor pseudoprogression following radiosurgery for vestibular schwannoma. Neuro Oncol 14:87-92, 2012

13. Henzel M, Gross MW, Hamm K, Surber G, Kleinert G, Failing T, et al: Significant tumor volume reduction of meningiomas after stereotactic radiotherapy: results of a prospective multicenter study. Neurosurgery 59:1188-1194, 2006

14. Iliadis G, Selviaridis P, Kalogera-Fountzila A, Fragkoulidi A, Baltas D, Tselis N, et al: The importance of tumor volume in the prognosis of patients with glioblastoma: comparison of computerized volumetry and geometric models. Strahlenther Onkol 185:743-750, 2009

15. Iwai Y, Yamanaka K, Ikeda H: Gamma Knife radiosurgery for skull base meningioma: long-term results of low-dose treatment. J Neurosurg 109:804-810, 2008

16. Kimball MM, Friedman WA, Foote KD, Bova FJ, Chi YY: Linear accelerator radiosurgery for cavernous sinus meningiomas. Stereotact Funct Neurosurg 87:120-127, 2009

17. Kohler BA, Ward E, McCarthy BJ, Schymura MJ, Ries LA, Eheman C, et al: Annual report to the nation on the status of cancer, 1975-2007, featuring tumors of the brain and other nervous system. J Natl Cancer Inst 103:714-736, 2011

18. Kollová A, Liscák R, Novotný J Jr, Vladyka V, Simonová 
G, Janousková L: Gamma Knife surgery for benign meningioma. J Neurosurg 107:325-336, 2007

19. Kondziolka D, Flickinger JC, Dade Lunsford L: Clinical research in stereotactic radiosurgery: lessons learned from over 10,000 cases. Neurol Res 33:792-802, 2011

20. Kondziolka D, Mathieu D, Lunsford LD, Martin JJ, Madhok R, Niranjan A, et al: Radiosurgery as definitive management of intracranial meningiomas. Neurosurgery 62:53-60, 2008

21. Kreil W, Luggin J, Fuchs I, Weigl V, Eustacchio S, Papaefthymiou G: Long term experience of gamma knife radiosurgery for benign skull base meningiomas. J Neurol Neurosurg Psychiatry 76:1425-1430, 2005

22. Kubo O, Chernov M, Izawa M, Hayashi M, Muragaki Y, Maruyama T, et al: Malignant progression of benign brain tumors after gamma knife radiosurgery: is it really caused by irradiation? Minim Invasive Neurosurg 48:334-339, 2005

23. Marta GN, Correa SF, Teixeira MJ: Meningioma: review of the literature with emphasis on the approach to radiotherapy. Expert Rev Anticancer Ther 11:1749-1758, 2011

24. Meijer OW, Weijmans EJ, Knol DL, Slotman BJ, Barkhof F, Vandertop WP, et al: Tumor-volume changes after radiosurgery for vestibular schwannoma: implications for follow-up MR imaging protocol. AJNR Am J Neuroradiol 29:906910,2008

25. Nakamura H, Jokura H, Takahashi K, Boku N, Akabane A, Yoshimoto T: Serial follow-up MR imaging after gamma knife radiosurgery for vestibular schwannoma. AJNR Am J Neuroradiol 21:1540-1546, 2000

26. Nakamura M, Roser F, Michel J, Jacobs C, Samii M: The natural history of incidental meningiomas. Neurosurgery 53:62-71, 2003

27. Nakasu S, Nakasu Y, Fukami T, Jito J, Nozaki K: Growth curve analysis of asymptomatic and symptomatic meningiomas. J Neurooncol 102:303-310, 2011

28. Pamir MN, Kiliç T, Belirgen M, Abacioğlu U, Karabekiroğlu $\mathrm{N}$ : Pituitary adenomas treated with gamma knife radiosurgery: volumetric analysis of 100 cases with minimum 3 year follow-up. Neurosurgery 61:270-280, 2007

29. Pan DH, Guo WY, Chang YC, Chung WY, Shiau CY, Wang LW, et al: The effectiveness and factors related to treatment results of gamma knife radiosurgery for meningiomas. Stereotact Funct Neurosurg 70 (Suppl 1):19-32, 1998

30. Pan HC, Cheng FC, Sun MH, Chen CC, Sheehan J: Prediction of volumetric data errors in patients treated with gamma knife radiosurgery. Stereotact Funct Neurosurg 85:184191, 2007

31. Park YG, Kim EY, Chang JW, Chung SS: Volume changes following gamma knife radiosurgery of intracranial tumors. Surg Neurol 48:488-493, 1997

32. Patil CG, Hoang S, Borchers DJ III, Sakamoto G, Soltys SG, Gibbs IC, et al: Predictors of peritumoral edema after stereotactic radiosurgery of supratentorial meningiomas. Neurosurgery 63:435-442, 2008

33. Pollock BE: Stereotactic radiosurgery for intracranial meningiomas: indications and results. Neurosurg Focus 14(5):e4, 2003

34. Pollock BE, Stafford SL, Link MJ, Garces YI, Foote RL: Single-fraction radiosurgery for presumed intracranial meningiomas: efficacy and complications from a 22 -year experience. Int J Radiat Oncol Biol Phys 83:1414-1418, 2012

35. Pollock BE, Stafford SL, Link MJ, Garces YI, Foote RL: Stereotactic radiosurgery of World Health Organization grade II and III intracranial meningiomas: treatment results on the basis of a 22-year experience. Cancer 118:1048-1054, 2012

36. Santacroce A, Walier M, Régis J, Liščák R, Motti E, Lindquist C, et al: Long-term tumor control of benign intracranial meningiomas after radiosurgery in a series of 4565 patients. Neurosurgery 70:32-39, 2012

37. Saraf S, McCarthy BJ, Villano JL: Update on meningiomas. Oncologist 16:1604-1613, 2011
38. Sheehan JP, Williams BJ, Yen CP: Stereotactic radiosurgery for WHO grade I meningiomas. J Neurooncol 99:407-416, 2010

39. Skeie BS, Enger PO, Skeie GO, Thorsen F, Pedersen PH: Gamma knife surgery of meningiomas involving the cavernous sinus: long-term follow-up of 100 patients. Neurosurgery 66:661-669, 2010

40. Sorensen AG, Patel S, Harmath C, Bridges S, Synnott J, Sievers A, et al: Comparison of diameter and perimeter methods for tumor volume calculation. J Clin Oncol 19:551-557, 2001

41. Starke RM, Nguyen JH, Rainey J, Williams BJ, Sherman JH, Savage J, et al: Gamma Knife surgery of meningiomas located in the posterior fossa: factors predictive of outcome and remission. J Neurosurg 114:1399-1409, 2011

42. Starke RM, Williams BJ, Hiles C, Nguyen JH, Elsharkawy MY, Sheehan JP: Gamma knife surgery for skull base meningiomas. J Neurosurg 116:588-597, 2012

43. Sughrue ME, Kane AJ, Shangari G, Rutkowski MJ, McDermott MW, Berger MS, et al: The relevance of Simpson Grade I and II resection in modern neurosurgical treatment of World Health Organization Grade I meningiomas. J Neurosurg 113:1029-1035, 2010

44. Sughrue ME, Rutkowski MJ, Aranda D, Barani IJ, McDermott MW, Parsa AT: Factors affecting outcome following treatment of patients with cavernous sinus meningiomas. J Neurosurg 113:1087-1092, 2010

45. Williams BJ, Yen CP, Starke RM, Basina B, Nguyen J, Rainey J, et al: Gamma Knife surgery for parasellar meningiomas: long-term results including complications, predictive factors, and progression-free survival. J Neurosurg 114:1571-1577, 2011

46. Wowra B, Stummer W: Efficacy of gamma knife radiosurgery for nonfunctioning pituitary adenomas: a quantitative follow up with magnetic resonance imaging-based volumetric analysis. J Neurosurg 97 (5 Suppl):429-432, 2002

47. Yang DY, Sheehan J, Liu YS, ChangLai SP, Pan HC, Chen CJ, et al: Analysis of factors associated with volumetric data errors in gamma knife radiosurgery. Stereotact Funct Neurosurg 87:1-7, 2009

48. Zada G, Pagnini PG, Yu C, Erickson KT, Hirschbein J, Zelman V, et al: Long-term outcomes and patterns of tumor progression after gamma knife radiosurgery for benign meningiomas. Neurosurgery 67:322-329, 2010

\section{Author Contributions}

Conception and design: Kondziolka, Harrison, Kano. Acquisition of data: Harrison. Analysis and interpretation of data: Kondziolka, Harrison, Kano. Drafting the article: Kondziolka, Harrison. Critically revising the article: all authors. Reviewed submitted version of manuscript: all authors. Approved the final version of the manuscript on behalf of all authors: Kondziolka. Statistical analysis: Harrison. Administrative/technical/material support: Kondziolka, Lunsford, Flickinger. Study supervision: Kondziolka, Kano.

\section{Supplemental Information}

\section{Previous Presentation}

A portion of this work was presented in oral form at the 2012 Annual Meeting of the Congress of Neurological Surgeons, October 6-10, 2012, in Chicago, Illinois.

\section{Correspondence}

Douglas Kondziolka, NYU Langone Medical Center, 530 First Ave., Ste. 8R, New York, NY 10016. email: douglas. kondziolka@nyumc.org. 